\title{
Troweling of Concrete Surfaces - Contemporary Methods
}

\author{
Izabela Major $^{1 *}$, Jarosław Kalinowski ${ }^{1}$ \\ ${ }^{1}$ Department of Technical Mechanics and Engineering Graphics, Faculty of Civil Engineering, Czestochowa University of \\ Technology, Akademicka 3 Street, 42-200 Częstochowa, Poland \\ * Corresponding author, e-mail: imajor@bud.pcz.pl
}

Received: 19 July 2019, Accepted: 22 September 2019, Published online: 27 November 2019

\begin{abstract}
The paper presents an analysis of the process of troweling concrete surfaces using the disc power trowel machines. The quantitative parameter of the disc effect of the disc is its geometric efficiency $S_{g}$. The algorithm for calculation of geometric efficiency $S_{g}$ by simulation method is presented. The analytical formulas for calculation of geometric efficiency $S_{g}$ for the solid disc and the ring for uniform linear motion at constant rotational velocity are presented.

The possibility of converting geometry of the working element to approximate geometry (in terms of geometric efficiency) with the form of concentric rings with center in the middle of the rotation of the disc is presented. The size of the ring was determined by a parameter called the filling factor $w$. This record allows to calculate the value of the geometric efficiency of the disc's effect by the analytical method as the sum of the geometric efficiency of all. The methodology of numerical calculation of the widths of overlapping of machining areas for neighboring disc tracks has been presented to ensure the highest homogeneity of machining. The adopted objective function to optimize the uniformity of machining is to minimize the index of standard deviation of the geometric efficiency $\varepsilon_{s g}$. The geometry of the real working elements most often used for troweling in the aspect of uniformity of machining was analyzed. The method of the optimization of geometry with the assumed kinematic parameters was indicated in order to obtain the best quality of surface machining.
\end{abstract}

\section{Keywords}

troweling, concrete surfaces, geometric efficiency

\section{Introduction}

The process of concrete troweling is used to improve the mechanical and functional properties of the concrete surface. Troweling process leads to increased impact resistance, improved surface roughness, and reduced abrasion [1, 2]. Very often, various types of admixtures are used to increase concrete strength $[3,4]$ or concrete blocks are filled with inserts affecting the insulating and vibration damping properties [5]. Nevertheless, an important issue related to the characteristics of concrete surfaces is the obtaining of their high equality and smoothness, which guarantees the increase of strength and quality of exploitation. Research on working techniques, e.g., floor top finishing and curing and in the resulting pore distribution on the concrete floor slab surface related to water absorbency [6].

The most frequently used tools are disc power trowel machines, characterized by a simple design and high efficiency [7]. The power trowel machines use rough troweling discs with different shapes of working elements, most often in the form of four rectangles, blades, whereas for the final troweling, solid circular discs are used. The quantitative parameter of the disc effect of the disc is its geometric efficiency $S_{g}$. The geometric efficiency at the point of the surface to be machined is defined as the length of the line of contact between the working elements and this point during the entire machining cycle. An example of the shape of the line of contact between the surface point and the surface of the disc is shown in Fig. 1. The values of mechanical parameters of the surface depend on the magnitude of the process determined by the geometric efficiency $S_{g}$.

\section{Algorithm for calculation of geometric efficiency using the simulation method}

The kinematics of the troweling disc consists of its movement on the processed surface in a progressive motion at linear velocity $V_{p}$ and the simultaneous rotation of the disc around its own axis at a rotational velocity $\omega$. The forward velocity vector of the disc $\overrightarrow{V_{p}}$ is constant at any point in the area of the disc's effect. The value of the linear $\overrightarrow{V_{\omega}}$ 


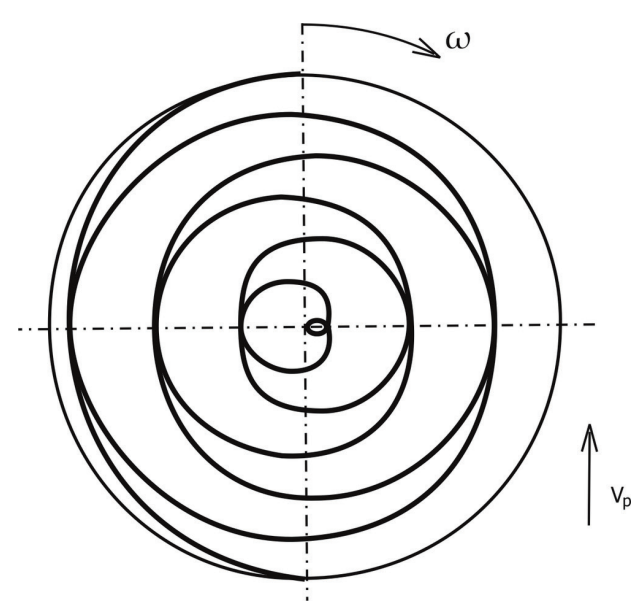

Fig. 1 The contact line of the disc with the point passing through the center of the disc after it has completely passed through this point [8]

velocity vector resulting from the rotational speed of the disc $\omega$ is directly proportional to the distance $r$ of the point from the center of rotation of the disc, which is defined by the formula $V_{\omega}=\omega_{r}$. The direction of this vector is perpendicular to the radius from the center of rotation, and its sense depends on the direction of rotation. The resultant velocity of the effect of the disc on the analyzed point $\overrightarrow{V_{w}}$ at a given position of the disc in relation to the analyzed point is the vector sum of the forward velocity of the disc $\overrightarrow{V_{p}}$ and the linear velocity resulting from the rotational $\frac{p}{V_{\omega}}$ velocity.

$\overrightarrow{V_{w}}=\overrightarrow{V_{p}}+\overrightarrow{V_{\omega}}$

The scheme of determination of the resultant velocity vector for a point in the area of the disc effect is shown in Fig. 2.

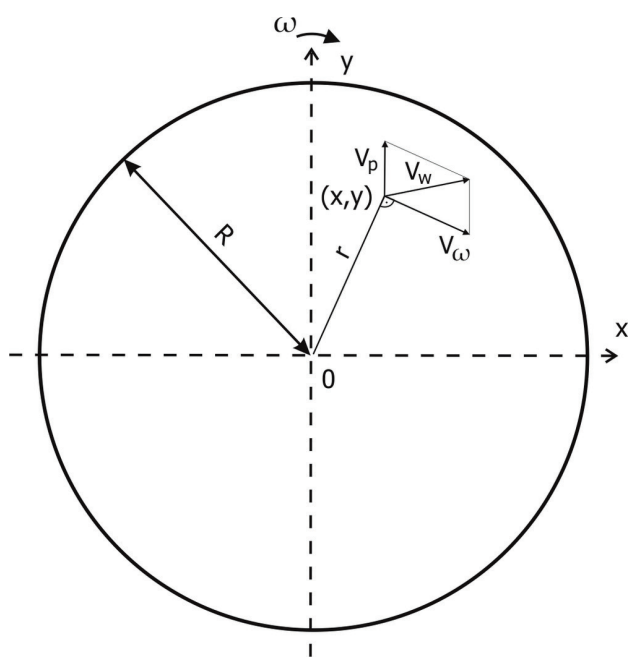

Fig. 2 Schematic diagram of composing the resultant velocity vector resulting from the forward and rotational velocities of the disc for any point with coordinates in relation to the disc center [8]
The algorithm for determining the geometric efficiency $S_{g}$ is based on the calculation of the sum of machining effects $S_{g d t}$ in short periods of time $d t$ into which the simulation time is divided. The position and kinematic parameters of the disc [9] are determined in each step of the simulation. If the position of the point analyzed coincides with the surface of the working element of the disc, the value of the momentary machining effect $S_{g d t}$ of the disc on the point being the product of the resultant velocity $V_{w}$ and the duration of the effect $d t$ is calculated. Otherwise, the value of $S_{g d t}$ takes the value of zero.

The velocity of disc effect on a point with coordinates $\mathrm{x}, \mathrm{y}$ in a rectangular system with the beginning in the center of the disc located as shown in Fig. 2 is calculated according to the formula:

$$
V_{w}(x, y)=\sqrt{V_{p}^{2}+2 V_{p} x \omega+y^{2} \omega^{2}+x^{2} \omega^{2}} .
$$

\section{Calculation of the geometric efficiency value for the solid disc and the ring using the analytical method for} uniform linear motion at constant rotational velocity The geometric efficiency $S_{g}$ of a circular disc after its complete passage through the tested point $P(x, y)$ is the sum of the products of the velocity of effect $V_{w}$ and the interaction times $d t$, which is defined by the formula:

$$
S_{g}(x)=\int_{t_{1}}^{t_{2}} V_{w}(x, t) d t
$$

The formula for the geometric efficiency $S_{g}$ for a point with abscissa of $\mathrm{x}$ is:

$$
S_{g}(x)=\int_{-\frac{\sqrt{R^{2}-x^{2}}}{V_{p}}}^{\frac{\sqrt{R^{2}-x^{2}}}{V_{p}}} \sqrt{V_{p}^{2}+2 V_{p} x \omega+t^{2} V_{p}^{2} \omega^{2}+x^{2} \omega^{2} d t} .
$$

After integration, the formula has the form:

$$
\begin{aligned}
& S_{g}(x)=\frac{1}{V_{p}} \sqrt{\left(R^{2}-x^{2}\right)\left(V_{p}^{2}+2 V_{p} \omega x+\omega^{2} R^{2}\right)} \\
& +\frac{\left(V_{p}+x \omega\right)^{2}}{2 \omega V_{p}} \ln \left(\frac{\sqrt{V_{p}^{2}+2 V_{p} \omega x+\omega^{2} R^{2}}+\omega \sqrt{R^{2}-x^{2}}}{\sqrt{V_{p}^{2}+2 V_{p} \omega x+\omega^{2} R^{2}}-\omega \sqrt{R^{2}-x^{2}}}\right) .
\end{aligned}
$$

The geometric efficiency of the interaction of an annular element with an outer radius of $R_{z}$ and an inner radius of $R_{w}$ after a single pass of the disc can be calculated using the principle of superposition as the difference in the efficiency of a disc with a radius of $R_{z}$ and the efficiency of a disc with a radius of $R_{w}$ as described in the formula: 


$$
S_{g}(x)=S_{g R z}(x)-S_{g R w}(x),
$$

where:

$S_{g R z}$ - geometric efficiency calculated for a disc with a radius $R_{z}$,

$S_{g R w}$ - geometric efficiency calculated for a disc with radius $R_{w}$.

After simplification, the formulae will adopt the following forms for individual cases:

for $|x| \in\left(0 ; R_{w}\right)$ :

$$
\begin{aligned}
& S_{g}=\frac{1}{V_{p}}\left(\begin{array}{l}
\sqrt{\left(R_{z}^{2}-x^{2}\right)\left(V_{p}^{2}+2 V_{p} \omega x+\omega^{2} R_{z}^{2}\right)}+ \\
-\sqrt{\left(R_{w}^{2}-x^{2}\right)\left(V_{p}^{2}+2 V_{p} \omega x+\omega^{2} R_{w}^{2}\right)}
\end{array}\right) \\
& +\frac{\left(V_{p}+x \omega\right)^{2}}{\omega V_{p}} \ln \left(\frac{\sqrt{V_{p}^{2}+2 V_{p} \omega x+\omega^{2} R_{z}^{2}}+\omega \sqrt{R_{z}^{2}-x^{2}}}{\sqrt{V_{p}^{2}+2 V_{p} \omega x+\omega^{2} R_{w}^{2}}+\omega \sqrt{R_{w}^{2}-x^{2}}}\right),
\end{aligned}
$$

for $|x| \in\left(R_{w} ; R_{z}\right)$ the formulae takes the form analogous as for the circle:

$$
\begin{aligned}
& S_{g}=\frac{1}{V_{p}} \sqrt{\left(R_{z}^{2}-x^{2}\right)\left(V_{p}^{2}+2 V_{p} \omega x+\omega^{2} R_{z}^{2}\right)}+ \\
& +\frac{\left(V_{p}+x \omega\right)^{2}}{2 \omega V_{p}} \ln \left(\frac{\sqrt{V_{p}^{2}+2 V_{p} \omega x+\omega^{2} R_{z}^{2}}+\omega \sqrt{R_{z}^{2}-x^{2}}}{\sqrt{V_{p}^{2}+2 V_{p} \omega x+\omega^{2} R_{z}^{2}}-\omega \sqrt{R_{z}^{2}-x^{2}}}\right),
\end{aligned}
$$

for $|x|>R_{z}$ geometric efficiency value is equal $S_{g}=0$.

\section{Calculation of approximate geometric efficiency values for any geometry using analytical formulae}

Disc geometry can be described as a system of surfaces of rings with centers in the center of the disc [10]. By dividing the solid disc into $\mathrm{n}$ concentric contacting ring areas that completely fill the disc as shown in Fig. 3, each ring is

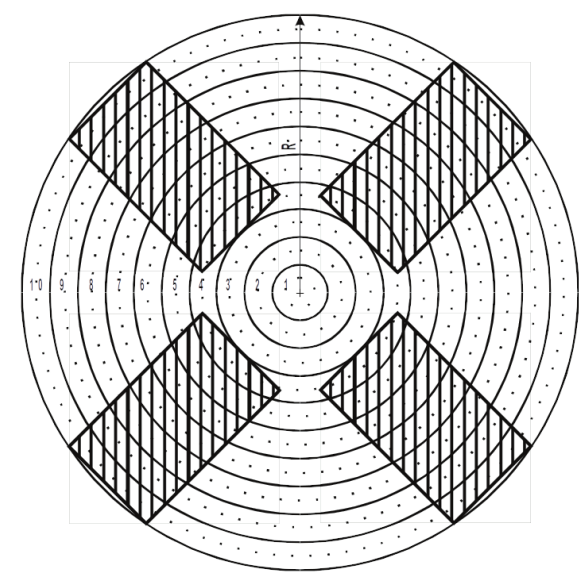

Fig. 3 Division of the troweling disc into rings to determine the filling factor assigned a filling factor $w$, which determines which part of the ring surface overlaps the working part. Using the analytical formulae to calculate the geometric efficiency of the ring by multiplying by the filling factor allows for a very effective calculation of the distribution of any geometric efficiency for any geometry of the troweling disc [8].

The geometric efficiency of the selected points of the surface being machined can be determined from the formulae:

$$
\begin{aligned}
& S_{1,1} \cdot w_{1}+S_{1,2} \cdot w_{2}+S_{1,3} \cdot w_{3}+\ldots+S_{1, n} \cdot w_{n}=S_{g 1} \\
& S_{2,1} \cdot w_{1}+S_{2,2} \cdot w_{2}+S_{2,3} \cdot w_{3}+\ldots+S_{2, n} \cdot w_{n}=S_{g 2} \\
& S_{3,1} \cdot w_{1}+S_{3,2} \cdot w_{2}+S_{3,3} \cdot w_{3}+\ldots+S_{3, n} \cdot w_{n}=S_{g 3}, \\
& S_{4,1} \cdot w_{1}+S_{4,2} \cdot w_{2}+S_{4,3} \cdot w_{3}+\ldots+S_{4, n} \cdot w_{n}=S_{g 4} \\
& S_{k, 1} \cdot w_{1}+S_{k, 2} \cdot w_{2}+S_{k, 3} \cdot w_{3}+\ldots+S_{k, n} \cdot w_{n}=S_{g k}
\end{aligned}
$$

where:

$S_{i, j}$ - geometric efficiency $S_{g}$ of the ring $j$ at point with index $i$,

$w_{i}$ - filling factor for ring $i$,

$S_{g i}$ - geometric efficiency $S_{g}$ for a point with index $i$.

The above formula may be presented in a matrix form convenient for numerical calculations:

$$
\left[\begin{array}{ccccc}
S_{1,1} & S_{1,2} & S_{1,3} & \ldots & S_{1, n} \\
S_{2,1} & S_{2,2} & S_{2,3} & \ldots & S_{2, n} \\
S_{3,1} & S_{3,2} & S_{3,3} & \ldots & S_{3, n} \\
S_{4,1} & S_{4,2} & S_{4,3} & \ldots & S_{4, n} \\
\ldots & \ldots & \ldots & \ldots & \ldots \\
S_{k, 1} & S_{k, 2} & S_{k, 3} & \ldots & S_{k, n}
\end{array}\right] \times\left[\begin{array}{c}
w_{1} \\
w_{2} \\
w_{3} \\
\ldots \\
w_{n}
\end{array}\right]=\left[\begin{array}{c}
S_{g 1} \\
S_{g 2} \\
S_{g 3} \\
S_{g 4} \\
\ldots \\
S_{g k}
\end{array}\right] .
$$

By changing the filling factors $w$, it is possible to optimize the geometry of the working element by adjusting the geometry to the assumed mean geometric efficiency $S_{g}$ and increasing the uniformity of machining. The time of calculations using the above simplification is by several orders of magnitude shorter than the simulation method [8].

\section{Determination of the parameter indicating the uniformity of machining}

The adopted objective function to optimize the uniformity of machining is to minimize the index of standard deviation, the value of which determines the uniformity of the effect of the disc on the surface to be machined. For the geometric efficiency values determined at $n$ points evenly distributed over the section, the index of standard deviation is described by the formula: 
$\varepsilon=\frac{\sigma}{\overline{S_{g}}}=\sqrt{\frac{\frac{1}{2}\left(S_{g 1}-\overline{S_{g}}\right)^{2}+\sum_{i=2}^{n-1}\left(S_{g i}-\overline{S_{g}}\right)^{2}+\frac{1}{2}\left(S_{g n}-\overline{S_{g}}\right)^{2}}{{\overline{S_{g}}}^{2}(n-1)}}$.

\section{Overlapping of areas of effect of disc elements}

In order to increase the uniformity of the effect, linear motion paths of the discs can be used, causing the occurrence of overlapping optimized areas of effect where the efficiencies sum up, as shown in Fig. 4. The sizes of the left and right overlays are selected in such a way as to minimize the value of the standard deviation index, and thus maximize the uniformity of the distribution of the geometric efficiency $S_{g}$.

The $S_{g}$ patterns for a single disc pass at the edges have zero values and increase at different speeds depending on the geometry used. In order to increase the uniformity of the effect, appropriately selected widths of overlapping of the impact zones on the left and right sides in which the geometric efficiencies are summed up are applied. The width of the reproducible part of the geometric efficiency graph that is representative of the whole of the graph is indicated in the Fig. 4 as $f$, which has a length equal to the four radii of the target minus the width of the areas of overlapping effect. By using the symmetry properties of the graph, machining parameters can be reduced by limiting the number of calculations to a width of $f_{1}$.

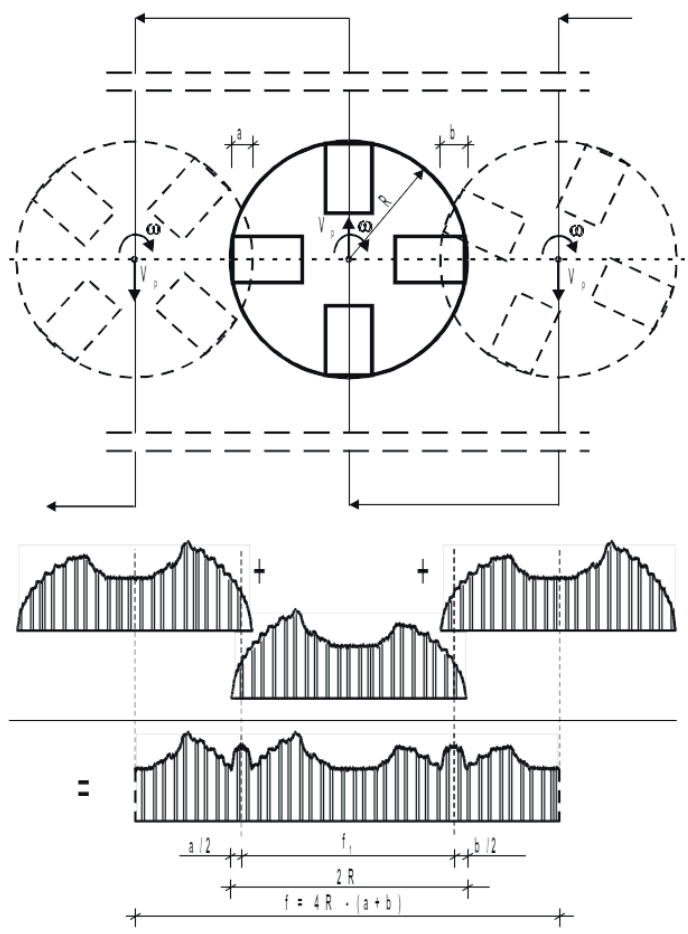

Fig. 4 Diagram of surface machining by means of disc tools when overlapping of machining zones [10]

\section{Example of selected geometries of working elements used in practice}

The most commonly used geometries of disc tools in practice are the four-blade geometry used for rough troweling and the solid disc for finishing troweling. Examples of distributions of geometric efficiency $S_{g}$ for a four-blade disc are shown in Figs. 5 and 6, whereas for a full disc - in Figs. 7 and 8. Figs. 6, 8 show the $S_{g}$ distribution with optimized machining overlap zones, which increases the uniformity of machining.

\section{Conclusions}

The use of straight parallel circular trowel routes with consideration for optimal overlaps allows for increasing the uniformity of surface machining. The use of a ring model that can be used to approximate any geometry and the

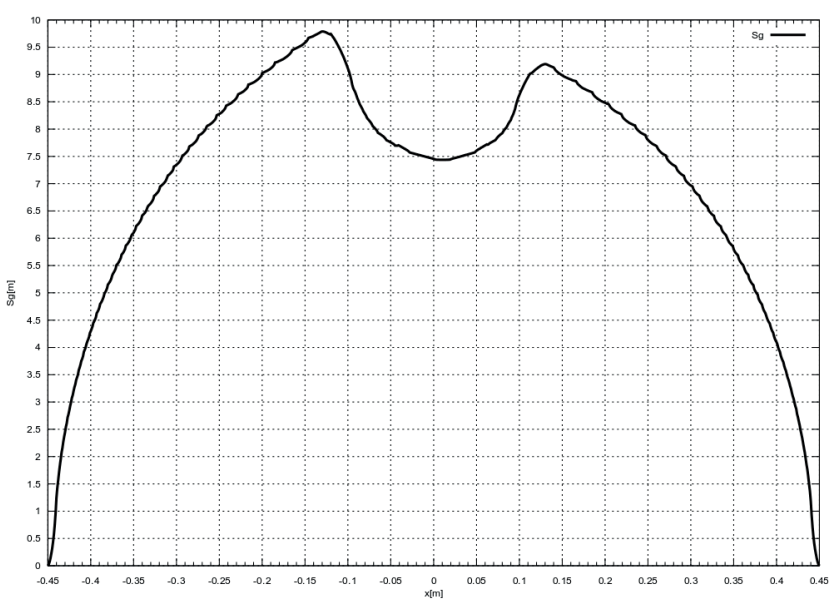

Fig. 5 Diagram of geometric efficiency $S_{g}$ for a single disc passage with working elements in the form of four rectangles $D=0.9 \mathrm{~m}, V_{p}=0.1 \mathrm{~m} / \mathrm{s}$, $\omega=9.425 \mathrm{rad} / \mathrm{s}$

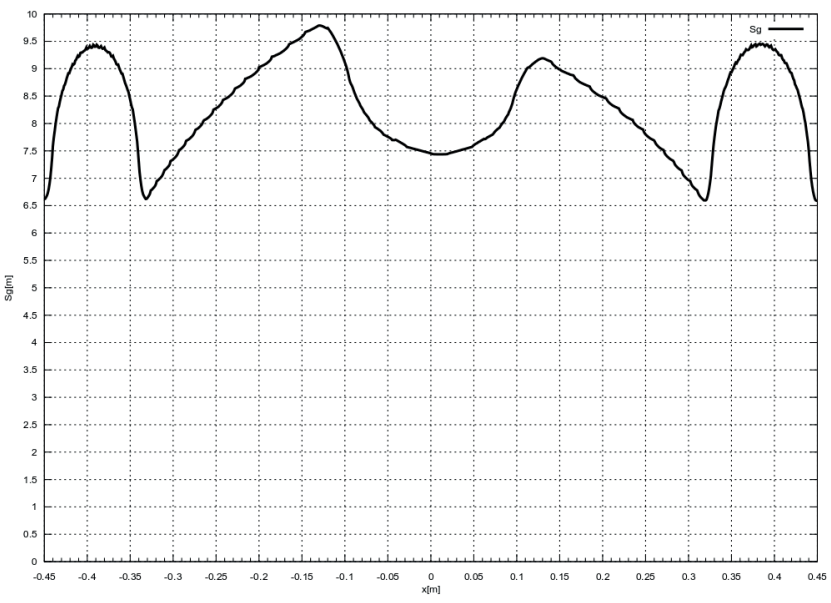

Fig. 6 Diagram of geometric efficiency $S_{g}$ for a disc with working elements in the form of four rectangles with optimally superimposed machining zones $D=0.9 \mathrm{~m}, V_{p}=0.1 \mathrm{~m} / \mathrm{s}, \omega=9.425 \mathrm{rad} / \mathrm{s}$ 


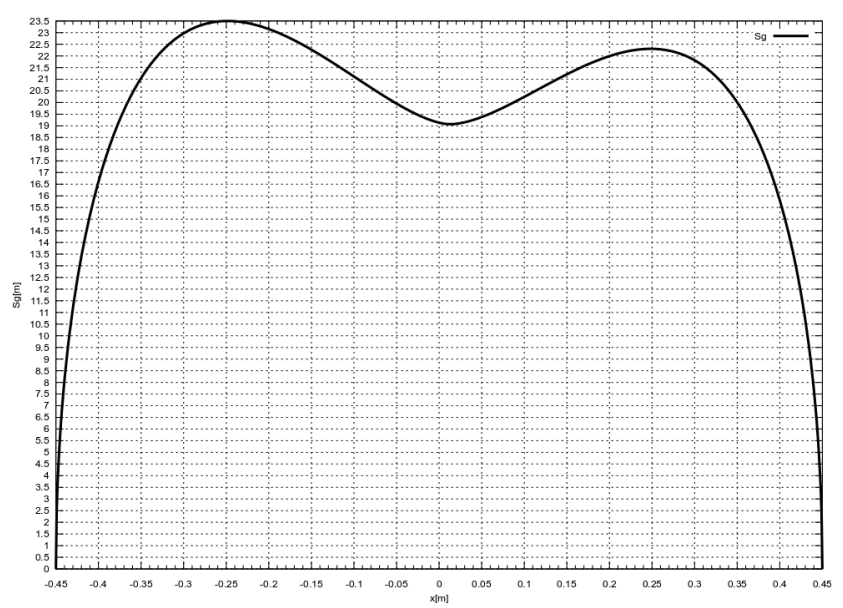

Fig. 7 Diagram of geometric efficiency $S_{g}$ for a single passage of a full $\operatorname{disc} D=0.9 \mathrm{~m}, V_{p}=0.1 \mathrm{~m} / \mathrm{s}, \omega=9.425 \mathrm{rad} / \mathrm{s}$

use of analytical formulae to calculate the geometric efficiency allows for the optimization of geometry. The use of the geometry of the working elements of the trowel disc adjusted to achieve the required geometric efficiency and at the same time increase the uniformity of machining with the assumed kinematic parameters allows for improving the machining quality. Quality of machining of concrete

\section{References}

[1] Kosiń, M., Grunsiok, K. "Obróbka mechaniczna powierzchni betonowych" (Mechanical machining of concrete surfaces), Zeszyty Naukowe Politechniki Częstochowskiej, Budownictwo, 16(166), pp. 77-82, 2010. (in Polish)

[2] ACI Committee 302 "302.1R-04: Guide for Concrete Floor and Slab Construction", American Concrete Institute, Farmington Hills, USA, 2004. [online] Available at: https://www.concrete.org/publications/internationalconcreteabstractsportal/m/details/id/13317 [Accessed: 10 July 2019]

[3] Katzer, J., Domski, J. "Characteristics of Concrete Based on Red Waste Ceramics and Reinforced by Steel Fibre", In: Fourth International Conference on Sustainable Construction Materials and Technologies SCMT4, Las Vegas, NV, USA, 2016, pp. 1-9.

[4] Javid, A. A. S., Nejad, M. A. A. "Packing density and surface finishing condition effects on the mechanical properties of various concrete pavements containing cement replacement admixtures", Construction and Building Materials, 141, pp. 307-314, 2017. https://doi.org/10.1016/j.conbuildmat.2017.03.021

[5] Major, M., Major, I., Kuchárová, D., Kuliński, K. "Reduction of Dynamic Impacts in Block Made of Concrete - Rubber Composites", Civil and Environmental Engineering, 14(1), pp. 61-68, 2018. https://doi.org/10.2478/cee-2018-0008

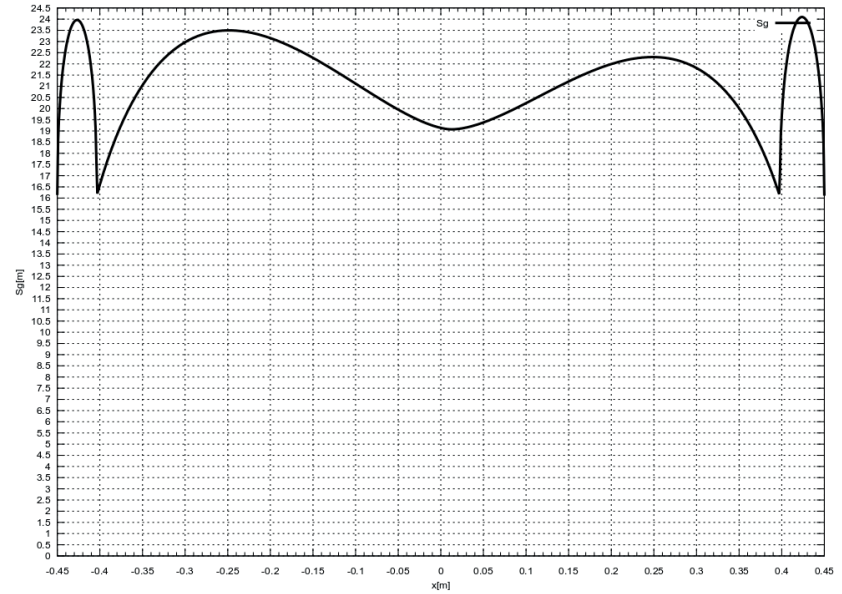

Fig. 8 Diagram of geometric efficiency $S_{g}$ for full disc with optimally overlapped machining zones $D=0.9 \mathrm{~m}, V_{p}=0.1 \mathrm{~m} / \mathrm{s}, \omega=9.425 \mathrm{rad} / \mathrm{s}$

surfaces can be indirectly determined by the uniformity of roughness of the treated surface, which depends on the geometric efficiency and consistency of the troweled concrete mix. Using the discs with optimal geometric parameters and an optimal path leads to the improvement in quality, durability and reduction of maintenance costs for concrete surfaces without additional investments.

[6] Yokoyama, Y., Yokoi, T., Ihara, J. "The effects of pore size distribution and working techniques on the absorption and water content of concrete floor slab surfaces", Construction and Building Materials, 50, pp. 560-566, 2014.

https://doi.org/10.1016/j.conbuildmat.2013.10.013

[7] Barszcz, A. "Maszyny do robót wykończeniowych i instalacyjnych" (Machines for finishing and installation works), Materiały Budowlane, 8, pp. 61-64, 1999. (in Polish)

[8] Kalinowski, J. "Obliczanie skuteczności geometrycznej tarczy zacierającej metodą analityczną" (Calculation of the geometrical efficiency of the trowelling disk using the analytical method), Zeszyty Naukowe Politechniki Częstochowskiej. Budownictwo, 24(174), pp. 167-173, 2018. (in Polish)

[9] Sradomski, W. "MATLAB, Praktyczny podręcznik modelowania" (MATLAB, A practical modeling guide), HELION, Gliwice, Poland, 2015. (in Polish)

[10] Kalinowski, J., Rajczyk, Z., Al-Mashadani, M. "Efficiency Analysis of the disc working element in reference of treatment technology of concrete surface" Zeszyty Naukowe Politechniki Częstochowskiej. Budownictwo, 15(165), pp. 107-118, 2009. (in Polish) 